\title{
Göçmenlerin Ülkemizdeki Sağlık Yüküne Etkisi ve Göçmenlere Bakış Açısı: Sağlık Personeli Aday Örneği
} The Effects of Immigrants on the Health Burden in Our Country and Their Perspective: Candidate Example of
Medical Personnel

\section{Beliz YEKELER KAHRAMAN ${ }^{1}$, Meltem ŞAHİN²}

\section{ÖZ}

$\mathrm{Bu}$ araştırma üniversite öğrencilerinin göçmenlere yönelik zenofobi algılarını ve göçmenlerin sağlık yükünü ne ölçüde etkiledikleri konusunda düşüncelerini tespit etmek amacıyla yapılmıştır. Tanımlayıcı nitelikteki bu çalışmaya 1493 öğrenciden 638 öğrenci katılmıştır. Öğrenciden veri toplamak için kullanılan anket, araştırmacılar tarafından literatür taraması yapılarak oluşturulan 14 soru ve Zenofobi ölçeğini içermektedir. Gerekli kurum izinleri alındı ve uygun istatistiki yöntemler kullanıldı. Öğrencilerin \%78.1'inin yaşadığ 1 yerde göçmen var iken, \%18.2'si göçmenlerden korktuğunu ifade etmişlerdir. Öğrencilerin \%84.1'i göçmenleri geçici misafir, ülkesiz kalan ve zulme uğrayan din kardeşi şeklinde olumlu görür iken, \%15.7'si olumsuz görüş paylaşmışlardır. Öğrencilerin $\% 71.5$ 'i göçmenlerin sağlık hizmetleri yükünü arttırdığını, \%58.2'si eradike olan hastalıkların yeniden ortaya çıkmasına sebep olduklarını, \%58'i aile planlamasına önem vermediklerini, \%38.1'i aşılamaya önem vermediklerini, \%28.8'i cinsel yolla bulaşan hastalıklarını arttırdıklarını belirtmişlerdir. Zenofobi ile ilgili yapılan çalışmalar çoğaltılmalıdır.

Anahtar Kelimeler: Sağlık, Sağlık Personeli, Zenofobi

\begin{abstract}
It was carried out in order to determine the perceptions of xenophobia of university students towards immigrants and to what extent they affect the health burden of immigrants. 638 students out of 1493 students participated in this descriptive study. The questionnaire used to collect data from the students, 14 questions created by the researchers through a literature review, and the Zenophobia scale were used. Necessary institutional permissions were obtained and appropriate statistical methods were used. While $78.1 \%$ of the students have immigrants in the place they live, $18.2 \%$ of them stated that they are afraid of immigrants. While $84.1 \%$ of the students view immigrants as temporary guests, stateless and persecuted religious siblings, $15.7 \%$ of them shared negative opinions. $71.5 \%$ of the students stated that immigrants increased the burden of health services, $58.2 \%$ caused the re-emergence of eradicated diseases, $58 \%$ did not attach importance to family planning, $38.1 \%$ did not attach importance to vaccination, $28.8 \%$ increased their sexually transmitted diseases they stated. Studies on zenophobia should be increased.
\end{abstract}

Keywords: Health, Health Personel, Zenophobi,

Çalışma için ilgili Üniversitenin Etik Kurulu’ndan ve araştırmanın yürütüleceği kurumdan yazılı izin alınmıştır.

${ }^{1}$ Öğr. Gör. Beliz YEKELER KAHRAMAN, Hemşirelik, Sağlık Bilimleri Üniversitesi Hamidiye Sağlık Hizmetleri Meslek Yüksekokulu, beliz.kahraman@sbu.edu.tr, yekeler_beliz@hotmail.com,0000-0003-3063-1658

${ }^{2}$ Öğr. Gör. Meltem ŞAHIN, Hemşirelik, Gümüşhane Üniversitesi Sağllk Hizmetleri Meslek Yüksekokulu, meltemdemir2929@ hotmail.com, 0000-0002-7808-5126 
İnsanı değerli kılan bulundukları mekân ile kurduğu bağdır. Göç, insan ve mekân arasındaki bağa zarar veren önemli unsurlardan biridir ${ }^{1}$. İnsanlık tarihi kadar eski olan göç; kişi veya toplulukların ekonomik, siyasi, eğitim ve sağlık nedenleriyle değişik kültürlerine yaşadıkları yerlerden kendi istekleri ya da mevcut zorunlu koşullar nedeniyle yer değiştirmelerdir ${ }^{2}$. Küreselleşme, bölgesel çatışmalar, savaşlar, yoksulluk gibi faktörlere ek olarak ulaşım ve iletişim imkânlarının teknolojinin gelişmesi ile daha ulaşılabilir ve kolay olmasından dolayı göç edenlerin sayısı giderek artmaktadır ${ }^{3}$. Birleşmiş Milletler Mülteciler Yüksek Komiserliği (UNHCR) 2018 y1lının sonunda dünyada 3,5 milyon sı ğınmacı, 41,3 milyon kendi ülkeleri içinde yerinden edilmiş kişi, 25,9 milyon mülteci ve 70,8 milyon zorla yerinden edilip başka bir bölgeye taşınmak zorunda kalan insan olduğunu bildirmiştir ${ }^{4}$.

Türkiye coğrafi yapısı, tarihsel, kültürel, ekonomik ve siyasal nedenlerinden dolayı son 30 y1ldır mülteci hareketliliğiyle yoğun bir şekilde karşı karşıya kalmaktadır ${ }^{5}$. Kuzey Afrika'da 2010 yılında meydana gelen Arap Baharı olarak bahsedilen bu olay sonucunda 2011 y1lında Suriye sinırlarını zorlayan bir şiddet durumu yaşanmış ve hatta milyonlarca insan ülkelerini bırakmak zorunda kalmıştır ${ }^{1}$. 2011 y1lından itibaren Türkiye'ye gelmeye başlayan Suriyeli mülteciler, zaman içinde toplumun her kesimini farklı açılardan etkilemişlerdir. Türkiye'ye göç eden Suriyelilerin sayısındaki büyük artış, göçün tesirinin genişlemesine ve aynı zamanda göçün etkisinin derinleşmesine de sebep olmuştur. Eğitim, ekonomi, toplumsal ve sosyal hayat başta olmak üzere farklı alanlarda göç ettikleri bölgelerin farklılaşmasına neden olmuşlardır'. 2019 Kasım ayı kayıtlarına göre Türkiye'de geçici koruma statüsündeki Suriyeli mülteci sayısı 3 milyon 691 bin 333'e ulaşmıştır ${ }^{7}$. Hem nüfusun fazla olması hem de Suriyeli mültecilerin büyük bir bölümünün Türkiye'ye kalıcı olarak yerleşmesi yerel halkı rahatsız edip göçmenlere karşı

\section{GÍRIȘ}

önyargıya, olumsuz tutumlara ve yabancı düşmanlığına yol açmaktadır.

Göçmenlerin ve mültecilerin gittikçe daha fazla karşılaştıkları, refahın önündeki en büyük engellerden biri ev sahibi ülkeye gelmeden çok önce başlayan zenofobik bakış açısıdır $^{8}$. Zenofobi kelimesi Yunanca'dan köken alan "xenos" ve "phobos" sözcüklerinden oluşmaktadır. "Xenos" yabanc1, "phobos" ise korku anlamina gelen kelimelerin oluşturduğu zenofobi sözcüğü de "yabanc1 korkusu" demektir". UNESCO ya göre zenofobi "belirli bir popülasyondaki yerlilere karşı düşmanlığın tavır yönelimi" olarak tanımlamaktadır ${ }^{7}$. Uluslararası Çalışma Örgütü (ILO)'ya göre ise zenofobi “ insanları toplumda veya ulusal kimliğe yabanc1 oldukları algısına dayanarak reddeden, dişlayan ve sik sik suçlayan tutumlar, önyargılar ve olumsuz davranışlar" dir ${ }^{10}$. Zenofobik düşünceler toplumda "öteki" ya da "yabancı" olarak görülen gruplara karşı hoşnutsuzluk ve nefret duygusundan beslenmektedir. Zenofobik düşüncelerin çıktıları öteki olarak adlandırılan grubun eğitim ve sağlik hizmetlerinden yararlanmalarının istenmemesi, grup üyelerinin iş yerlerinde çalıştırılmak istenmemesi, ev kiralamalarında engeller çıkarılması gibi davranışlar olabilmektedir. Zenofobinin hedefi olan kişilere ilişkin korku, çoğu zaman gerçeği yansıtmadığı gibi, çoğunlukla yanlış olan inançlara dayanmaktadır. Ayrıca zenofobi, kişinin kendi ait olduğu kültürünü, etnik kökenini ya da dinini üstün görmek ile de bağlantılıdır. Öteki olarak nitelendirilen gruba karşı ayrımcılık, nefret veya şiddet gibi davranışlar zenofobinin göstergeleri olarak ele alınabilir ${ }^{6}$.

$\mathrm{Bu}$ tür nefret ve şiddet içeren düşünceler toplumda ayrımcılığa yol açarak toplumun refah düzeyinin düşmesine neden olmaktadır. Toplumun ümidi ve geleceği gençlerdir. Kişilik oluşumu, düşünsel gelişme gençlik döneminde verilen eğitim ve yönelişler sonucunda ortaya çıkmaktadır. Bir ülkenin siyasal rejimi ve gelişme düzeyi ne olursa olsun gençlerin eğitimi ve görüşleri her ülke 
için önemlidir. Gençlerine kıymet verip, onların donanımlı ve kaliteli bir eğitim alarak yetişmelerini sağlayan toplumlar geleceğe daha güvenle bakarlar. $\mathrm{Bu}$ nedenle bu çalışma sağlık personeli olarak atanıp topluma hizmet etmek ile yükümlü üniversite öğrencilerinin göçmenlere yönelik zenofobi algılarını ve göçmenlerin sağlık yükünü ne ölçüde etkiledikleri konusunda düşüncelerini tespit etmek amaciyla yapılmıştır.

\section{MATERYAL VE METOT}

\section{Araştırmanın Tipi, Evren ve Örneklem}

Tanımlayıcı nitelikteki bu çalışma etik kurul ve gerekli kurum izinleri alındıktan sonra Gümüşhane Üniversitesi Sağlık Hizmetleri Meslek Yüksekokulunda okuyan (Diyaliz Program1, Fizyoterapi Program1, Yaşlı Bakımı Programı, Çocuk Gelişimi Programı, İlk ve Acil Yardım programı, Tibbi Laboratuvar Programi) 1493 öğrenciden $638 \quad(\% 42,7) \quad$ öğrenciye yapılmıştır.

\section{Verilerin Toplanması}

Veriler çalışmaya katılmayı kabul eden öğrencilere anket dağıtılarak Mayıs 2019 tarihinde toplanılmıştır. Örneklem seçimine gidilmeyip, çalışmaya gönüllü olarak katılmayı kabul eden öğrencilerden sözlü onam alınarak çalışmaya dahil edilmiştir. Sınıfta yüz yüze uygulanan anket formları, ders başlamadan 15 dakika içinde dolduruldu ve toplandi.

\section{Veri Toplama Araçları}

Öğrenciden veri toplamak için kullanılan anket, araştırmacılar tarafından literatür taraması yapılarak oluşturulan 14 sorudan ve yazarından izin alınarak, geçerlilik güvenirliliği yapılan bir ölçek kullanılmıştır. Ölçeğin geçerlilik güvenirliliği Bozdağ ve Kocatürk tarafından 2017 yılında yapılan cronbach alfa değeri .86 olan Zenofobi ölçeğinden oluşmuştur. Bu örneklem için ise cronbach alfa değeri .89 bulunmuştur. Ölçek 3 faktörden ("korku, nefret ve aşağılama") ve beşli likert tipinde 18 maddeden oluşmaktadır. Katılımcılar ölçekte bulunan her bir maddeyi dikkat ederek okuması ve o maddenin karşısındaki "Tamamen Kat1liyorum", "Kat1liyorum", "Kismen Katıliyorum", "Katılmıyorum" ve "Hiç Katılmıyorum" şeklindeki beş seçenekten kendilerine en uygun seçeneği işaretlemeleri istenmiştir. Ölçekteki ayrı ayrı her bir madde "Tamamen Katıllyorum" seçeneği için 5 puan, "Katılıyorum" seçeneği için 4 puan, "Kısmen Katıliyorum" seçeneği için 3 puan, "Katılmıyorum" seçeneği için 2 puan ve "Hiç Katılmıyorum" seçeneği için 1 puan şeklinde puanlanmaktadır. 7. ve 11. maddeler ters puanlanmaktadır. Ölçekten alınabilecek en düşük puan 18, en yüksek puan ise 90 olup, yüksek puan zenofobi düzeyinin yüksek olduğu, düşük puan ise zenofobi düzeyinin düşük olduğu anlamına gelmektedir.

\section{Araştırmanın Etik Yönü}

Çalışma da kullanılan ölçek için ilgili araștırmacılardan gerekli izin alındı. Çalışmaya katılmayı kabul eden öğrencilerden de sözlü onam alınarak çalışmaya dahil edildi. Araştırmanın yapılabilmesi için kurum (Sayı Numarası: 21452481-100-E.8709, Tarih: 11/03/2019) ve etik kurul izinleri tamamlandi. Etik kurul izni Gümüşhane Üniversitesi Bilimsel Araştırma ve Yayın Etiği Kurulu'ndan alındı (Say1 Numaras1: 95674917-108.99-E.9740, Tarih: 19/03/2019).

\section{Verilerin Analizi ve Yorumu}

Veriler SPSS paket programında frekans ve yüzde değerleri hesaplanmıştır. Gruplar aras1 farklılıkların olduğu durumlarda, ortaya çıkan farkın hangi gruplar arasında olduğunu saptamak amaciyla için Tukey çoklu karşılaştırma testi kullanılmıştır. Değişkenler ile puanlar arasında fark olup olmadığına grup sayısı iki ise bağımsız t testi, grup sayısı ikiden fazla ise One way ANOVA ile test edilmiştir. Kolmogorov Smirnov testine göre dağılımın normal olduğu, varyansların eşit olduğu tespit edilmiştir. Verilerin analizinde anlamlılık düzeyi $p<, 05$ olarak belirlenmiştir. 


\section{Araştırmanın Sınırlılıkları}

Araştırmanın önlisans eğitimi alan ögrencilerle, anket formu ile sadece belli bir üniversite evren alınarak belli bir tarihte yapılıyor olması araştırmanın sınırlılıklarıdır.
Ayrıca bu araştırmanın kapsama oranı düşük olduğundan istatistiksel olarak anlamlı bulguların neden sonuç ilişkisi olarak yorumlanması güçtür.

\section{BULGULAR VE TARTIŞMA}

Tablo 1. Çalışmaya Katılan Öğrencileri Göçmenlere Yönelik Düşünceleri

\begin{tabular}{llrr}
\hline & & N & \multicolumn{1}{c}{$\%$} \\
\hline Yaşadığınız yerde & Evet & 498 & 78,1 \\
göçmen var mı? & Hayır & 140 & 21,9 \\
\hline Göçmenlerden korkar & Evet & 116 & 18.2 \\
mısınız? & Hayır & 522 & 818 \\
\hline Göçmenlerle ilgili & Evet & 442 & 69,3 \\
medyada olumsuz & Hayır & 39 & 6,1 \\
haber var mı? & Bilmiyorum & 157 & 24,6 \\
\hline Göçmenler sağlık & Evet & 456 & 71,5 \\
hizmetlerinin yükünü & Hayır & 59 & 9,2 \\
arttırıyor mu? & Bilmiyorum & 123 & 19,3 \\
\hline Eredike olan & Evet & 371 & 58,2 \\
hastalıkların yeniden & Hayır & 33 & 5,2 \\
ortaya çıkmasına & Bilmiyorum & 234 & 36,7 \\
neden olmakta mıdır? & & & \\
\hline Göçmenler aile & Evet & 20 & 3,1 \\
planlamasına önem & Hayır & 370 & 58 \\
veriyor mu? & Bilmiyorum & 248 & 38,9 \\
\hline Göçmenler aşılamaya & Evet & 20 & 3,1 \\
önem veriyor mu? & Hayır & 243 & 38,1 \\
& Bilmiyorum & 375 & 58,8 \\
\hline Göçmenler cinsel yolla & Evet & 184 & 28,8 \\
bulaşan hastalıkları & Hayır & 13 & 2 \\
arttırdı mı? & Bilmiyorum & 441 & 69,1 \\
\hline & Toplam & $\mathbf{6 3 8}$ & $\mathbf{1 0 0 . 0}$ \\
\hline & & &
\end{tabular}

Çalıșmaya katılan öğrencilerin yaș ortalamas1 20,16 $\pm 1,59$ olup, \%73'ü k1z, \%27'si erkek, \%70'i 1. sınıf öğrencisi, $\% 29,9$ 'u 2.sınıf öğrencisidir. \%18'i ilk ve acil yardım programı, \%15'i çocuk gelişimi program1, \%14,4'ü fizyoterapi program1, \%32'si tıbbi laboratuvar programı, \%12,2'si yaşlı bakımı programı, \%8,3'ü diyaliz programı öğrencisidir. Öğrenciler gelirlerini giderleri ile karşılaştırdığında \%35,7'si kötü, $\% 55,8$ 'i orta şeklinde ifade ederken, \%8,5'i iyi olarak belirtmiştir. Öğrencilerin $\% 78,1$ 'inin yaşadığı yerde göçmen var iken, \%18,2'si göçmenlerden korktuğunu ifade etmişlerdir. Öğrencilerin \%84,1'i göçmenleri geçici misafir, ülkesiz kalan ve zulme uğrayan din kardeşi şeklinde olumlu görür iken, \%15,7'si olumsuz görüş paylaşmışlardır. Öğrencilerin $\% 71,5^{\prime} i$ göçmenlerin sağlık hizmetleri yükünü arttırdığını, \%58,2'si eradike olan hastalıkların yeniden ortaya çıkmasına sebep olduklarını, \%58'i aile planlamasına önem vermediklerini, \%38,1'i aş1lamaya önem vermediklerini, \%28,8'i cinsel yolla bulaşan hastalıklarını arttırdıklarını belirtmişlerdir (Tablo 1).

Tablo 2. Üniversite Öğrencilerinin Zenofobi Ölçeği Puanlarının Cinsiyete Göre Karşılaştırılması

\begin{tabular}{lllllll}
\hline Gruplar & N & Ort. & S & sd & t & P \\
\hline Kız & 460 & 49,6 & 12,28 & \multirow{2}{*}{630} & - & \multirow{2}{*}{0,46} \\
Erkek & 172 & 51,8 & 12,74 & & 2,001 & \\
\hline
\end{tabular}

$N=$ Sayl, Ort. $=$ Ortalama,$\quad S=$ Standart sapma, $\quad s d=$ Serbestlik derecesi

Tablo 2 incelendiğinde çalışmaya katılan öğrencilerin cinsiyetleri ile zenofobi ölçeğinden almış oldukları puanlardaki farkın anlamlı olup olmadığını bulmak için yapılan t testi sonucunda, k1z öğrencilerin puanları ortalaması (Ort. K $1 \mathrm{z}=49,6 \pm 12,28$ ) ile, erkek öğrencilerin puanları ortalaması (Ort. Erkek $=51,8 \pm 12,74)$ arasında anlamlı bir fark bulunmuştur $[\mathrm{t}(630)=-2.001, \quad \mathrm{p}=0,046$, $\mathrm{p}<0,05]$. K1z öğrencilerin erkek öğrencilere nazaran zenofobi ölçek puanları daha düşük bulunmuştur.

Tablo 3 incelendiğinde gelir durumları ile zenofobi ölçek puanı arasında farklılık olup olmadığını saptamak için tek yönlü varyans analizi (ANOVA) ile karşılaştırılmıştır. Zenofobi ölçeğine göre gelir durumu gider durumu ile karşılaştırıldığında kendini kötü olarak değerlendiren öğrencilerin ortalaması (Ort. 51,28 $\pm 12,4$ ), gelir durumu gider durumu ile karşılaştırıldığında kendini orta olarak değerlendiren öğrencilerin ortalaması (Ort. 49,04 $\pm 12,05$ ), gelir durumu gider durumu ile karşılaştırıldığında kendini iyi olarak değerlendiren öğrencilerin ortalaması (Ort. 53,29 \pm 13,9) en az ikisi arasındaki fark istatistiksel olarak anlamlı bulunmuştur $\left[\mathrm{F}_{(2-}\right.$ 
629) $=4,089, \mathrm{p}<0.05]$. Sonuç olarak ekonomik

öğrencilere göre zenofobi ölçek puanları düzeyleri orta olan öğrencilerin iyi olan anlamlı olarak daha düşük bulunmuştur.

Tablo 3. Üniversite Öğrencilerinin Gelir Durumlarının Zenofobi Ölçeği Puanına Göre Karşılaştırılması

\begin{tabular}{|c|c|c|c|c|c|c|}
\hline Ölçek & $\begin{array}{l}\text { Varyansın } \\
\text { Kaynağı }\end{array}$ & $\begin{array}{r}\text { Kareler } \\
\text { Toplamı }\end{array}$ & sd & $\begin{array}{r}\text { Kareler } \\
\text { Ortalaması }\end{array}$ & $\mathbf{F}$ & $\mathbf{p}$ \\
\hline \multirow[t]{3}{*}{ Zenofobi } & Gruplar arası & 1253,43 & 2 & 626,718 & 4,089 & ,017 \\
\hline & Gruplar içi & 96405,57 & 629 & 153,268 & & \\
\hline & Toplam & 97659,01 & 631 & & & \\
\hline
\end{tabular}

Tablo 4. Üniversite Öğrencilerinin Göçmenlerden Korkma Durumlarının Zenofobi Ölçeği Puanına Göre Karşılaştırılması

\begin{tabular}{llrllll}
\hline Gruplar & N & Ort. & S & sd & t & p \\
\hline Evet & 111 & 56,5 & 13,03 & 629 & 6,067 & 0,000 \\
Hayır & 520 & 48,8 & 11,9 & & & \\
\hline $\begin{array}{l}N=\text { Sayl, } \\
\text { derecesi }\end{array}$ & Ort. $=$ Ortalama, & S= $=$ & Standart & sapma, & sd $=$ & Serbestlik \\
\end{tabular}

Tablo 4 incelendiğinde araştırmaya katılan öğrencilerin göçmenlerden korkma durumlarına ile zenofobi ölçeğinden almış oldukları puanlardaki farkın anlamlı olup olmadığını tespit etmek üzere yapılan bağımsız örneklemler için $t$ testi sonucunda, evet şeklinde cevap veren öğrencilerin puanları ortalaması ile (Ort. 56,5 $\pm 13,03$ ), hayır şeklinde cevap veren öğrencilerin puanları ortalaması (Ort. 48,8 $\pm 11,9$ ) arasında anlamlı bir fark bulunmuştur $\left[t_{(629)}=6,067\right.$, $\mathrm{p}=0,000, \quad p<0,05]$. Sonuç olarak göçmenlerden korkanların zenofobi ölçek puanları anlamlı şekilde yüksek olduğu bulunmuştur.
Tablo 5 incelendiğinde medyada olumsuz haber varlığının ile zenofobi ölçek puanı arasında farklılık olup olmadığını tespit etmek için tek yönlü varyans analizi (ANOVA) ile karşılaştırılmıştır. Medyada olumsuz haber varlığı ile zenofobi ölçeği karşılaştırıldığında "evet" şeklinde cevap veren öğrencilerin ortalaması (Ort. $51,08 \pm 12,7)$, "hayır" şeklinde cevap veren öğrencilerin ortalaması (Ort. 48,02 $\pm 1,5$ ), "bilmiyorum" şeklinde cevap veren öğrencilerin ortalaması (Ort. 48,30 $\pm 11,6$ ) en az ikisi arasındaki fark istatistiksel olarak anlaml 1 bulunmuştur $[F(2-627)=3,488$, $\mathrm{p}<0,05]$. Sonuç olarak medyada olumsuz haber varlığına "evet" cevabını verenler ile "bilmiyorum" cevabinı verenler arasında anlamlı bir ilişki bulunmuştur. Medyada olumsuz haber verenlerin çoğunlukta olduğunu ifade eden öğrencilerin zenofobi ölçek puanları daha yüksek bulunmuştur.

Tablo 5. Üniversite Öğrencilerinin Medyada Olumsuz Haberlerin Varlığının Zenofobi Ölçeği Puanına Göre Karşılaştırılması

\begin{tabular}{llrrrrr}
\hline Ölçek & Varyansın & $\begin{array}{r}\text { Kareler } \\
\text { Toplamı }\end{array}$ & sd & $\begin{array}{r}\text { Kareler } \\
\text { Ortalaması }\end{array}$ & F & p \\
& Kaynağı & 1073,43 & 2 & 536,702 & 3,488 &, 031 \\
\hline Zenofobi & Gruplar arası & 96467,23 & 627 & 153,855 & & \\
& Gruplar içi & $\mathbf{9 7 5 4 0 , 6 4}$ & $\mathbf{6 2 9}$ & & & \\
& Toplam & & & & & \\
&
\end{tabular}

Göç olayı hem göç edilen yerde yaşayanlar hem de göç edenler için önemli toplumsal sorunlardan bir haline gelmektedir. Göçmenlerden korkanların zenofobi ölçek puanları anlamlı şekilde yüksek olduğu bulunmuştur. Fakat buna rağmen müslüman olmaları ve zulme uğramaları Türkiye'de kabul görmelerini pekiştiren bir durumdur. Suriye'den gelen göçmenleri ülkesiz kalan, din kardeși, geçici misafir gibi tanımlamalar, olumsuz görüş bildirenlere göre daha yüksektir. Yapılan çalışmalara bakıldığında ise; 59 ülkede 50 bin kişiye yapılan çalışmada göçmenliğe karşı çıkanların oranı 
dünyada \%38 iken, Türkiye'de \%61 olarak bulunmuştur $^{11} \cdot \mathrm{Bu}$ araştırmada yaş parametresine göre Suriyeli Göçmenlere yönelik tutumlarda anlamlı bir farklılık görülmemiştir. Alanda yapılan çalışmalara bakıldığında Ekonomi ve Dış Politika Araştırmalar Merkezinin 2013 yılı Kasım ayında Türkiye genelinde 18 yaş üstü 1515 kişi ile yaptığı kamuoyu araştırmasında; Suriye'li sığınmacıları istemeyenler \%86 olarak bildirmiştir. Çalışmada cinsiyet değişkenine göre değerlendirildiğinde; k1z öğrencilerin erkek öğrencilere göre zenofobi ölçek puanları daha düşük bulunmuştur. Alanda yapılan çalışmalara bakıldığında; son zamanlarda yapılan araştırmalarda cinsiyetin göçmen karşıtı tutumları açıklamada etkisinin olmadığı ya da düşük düzeyde etkisinin olduğu belirtilmiştir ${ }^{12,13}$. Fakat grup tehdidin de zenofobi değişkenine bakıldığında; erkeklerde zenofobinin daha yüksek düzeyde olduğunu belirten çalışmalar bulunurken zenofobinin kadınlarda daha fazla olduğu sonucuna ulaşan çalışmalar da mevcuttur ${ }^{13-16}$. Çalışmada öğrencilerin zenofobi düzeylerinin okudukları bölüme göre farklılaşmadığ 1 sonucuna ulaşılmıştır. Kişilerin eğitim seviyeleri fark etmeksizin yabancılara yönelik korku ve nefretleri benzer olmakta, eğitim durumlarına göre değişmemektedir ${ }^{17 .}$

Göçmenlerin ülkemizde yok olan hastalıklara neden olduğunu düşünen kişilerin zenofobik ölçeği puanlarının yüksek olduğu görülmüştür. Çalışmaya katılan öğrencilerin yarıdan fazlası eradike olan hastalıkların yeniden ortaya çıkmasına sebep olduklarını ifade etmiştir. Dünya Sağlık Örgütü Avrupa Ofisi'nin raporuna göre, göç ve bulaşıcı hastalıkların bir ülkeden başka bir ülkeye taşınması arasında bir ilişki olduğuna dair yaygın bir alg1 olmasına rağmen aralarında sistematik bir ilişki bulunmamaktadır ${ }^{17}$. Göçmenlerde gelir düzeyinin düşük olması, sağlık sigortalarının bulunmaması, dil sorunu, aynı evde çok sayıda bireyin yaşaması, hijyen problemleri, yaşanılan olumsuzluklara ve şiddete bağlı gelişen ruhsal bozukluklar, temiz içme suyu sağlanamaması, atıkların uzaklaştırılamaması ve beslenme gibi faktörler de göç eden bireylerin sağlık durumlarını olumsuz yönde etkilemektedir. Tüm bu problemlere ilaveten işsizlik ve yoksullukla birlikte hastalıkların patlamasına neden olmakta ve günümüzde mesele olmayan hastalıklar yeniden sorun olmaya başlamaktadır ${ }^{18}$.

Çalışmaya katılan öğrencilerin yarıdan fazlası göçmenlerin aile planlamasına önem vermediklerini ifade etmişlerdir. Göçmen kadınlar sahip oldukları statünün devamlılığı için fazla sayıda çocuk doğurmak eğilimindedirler. $\mathrm{Bu}$ nedenle aile planlaması hizmetlerinden yararlanma da düşük olmaktadır $^{19}$. Çalışmada medyada olumsuz haber verenlerin çoğunlukta olduğunu ifade eden öğrencilerin zenofobi ölçek puanları daha yüksek bulunmuştur. Kolukırık tarafından 2009 yılında yapılan çalışmaya göre de; medyada yapılan haberlerin metin içeriklerine bakılmış ve göç ile ilgili yapılan haberlerde göçmenleri "öteki" olarak tanımladıkları, kamuoyunda olumsuz olarak algılanmasını sağladıkları tespit edilmiştir ${ }^{20}$.

\section{SONUÇ VE ÖNERÍLER}

Zenofobi bireysel ve toplum sağlı̆̆ üzerindeki olumsuz etkilerinin yanında hem halk sağlığı hem de politik açıdan sorun oluşturmaktadır. Kültürün entegrasyonu ve anlayışı destekleyen politikalar toplum sağlığını iyileştirmek için şarttır. Öğrencilere gerekirse zenofobi kavramı konusunda psiko- eğitsel grup çalışmaları yapılmalı ve bu çalışmalarda zenofobik düşünce, tutum ve davranışların azaltılması amaçlanmalıdır. zenofobi kavramı yurt içinde yeni elen alınan bir kavram olduğu için konu ile ilgili yapılan çalışma sayısı sınırlıdır. Zenofobi ile ilgili yapılan çalışmalar çoğaltılmalıdır. 


\section{KAYNAKLAR}

1. Ekici, S. ve Tuncel, G. (2015). "Göç ve İnsan". Birey ve Toplum, 5 (9), 9-22.

2. Aslan, Ş. ve Ulutaş, D.A. (2018). "Sağlık Açısından Göç ve Yaşl1lık". Göç Araştırmaları Dergisi, 4 (1), 10-29.

3. Tuzcu, A. ve Ilgaz, A. (2015). "Göçün Kadın ve Ruh Sağlığ Üzerine Etkileri”. Psikiyatride Güncel Yaklaşımlar, 7 (1), 5667.

4. Birleşmiş Milletler Mülteciler Yüksek Komiserliği. (UNHCR). Erişim: https://www.unhcr.org/tr/unhcr-turkiyeistatistikleri. Erişim tarihi: 20.11.2019.

5. Saçan, S, Cizdan, G. ve Tabak, H.D. (2017). "Aydın Halkının Suriyeli Göcmenlere Yönelik Bakıs Açısının İncelenmesi”. Adnan Menderes Üniversitesi Sağlık Bilimleri Fakültesi Dergisi, 1 (1), 28-38.

6. Aydın, Z.D. (2019). "Yetiskinlerde Zenofobi, Empati Düzeyi ve Suriyeli Çocukların Türk Eğitim Sistemine Dahil Edilmelerine İlişkin Algılar". İstanbul Üniversitesi Cerrrahpaşa, Lisansütü Eğitim Enstitüsü, Yüksek Lisans Tezi, İstanbul.

7. United Nations Education, Science and Culture Organization. Xenophobia. http://www.unesco.org/new/en/social-andhuman-sciences/themes/international-migration/glossary /xenophobia/Accessed 11.12.2020.

8. Suleman, S, Garber, K.D. and Rutkow, L. (2018). "Xenophobia as a Determinant of Health: An Integrative Review". J Public Health Pol, 39, 407-423.

9. Bozdağ, F. ve Kocatürk, M. (2017). "Zenofobi Ölçeği’nin Geliştirilmesi: Geçerlilik ve Güvenirlik Çalışmaları". The Journal of International Social Research, 10 (52), 615-620.

10. International Labour Office. International migration, racism, discrimination and xenophobia. Geneva. https://publications.iom.int/system/files/pdf/internatio nal_migration_racism.pdf. Accessed Aug 2001.
11. Ünal, S. (2014). "Türkiye'nin Beklenmedik Konukları: "Öteki” Bağlamında Yabancı Göçmen ve Mülteci Deneyimi”. Journal of World of Turks, 6 (3), 65-89.

12. Burjanek, A. (2001). "Xenophobia Among the Czech Population in the Context of PostCommunist Countries and Western Europe". Czech Sociological Review, 9 (1), 53-67.

13. Nastuta, S. and Tompea, A.D. (2011). "Who is Afraid of Immigrants?”. Sfera Politicii, 12 (166), 35-44.

14. Hjerm, M. (2009). "Anti-Immigrant Attitudes and Crossmunicipal Variation in the Proportion of Immigrants". Acta Sociologica, 52 (1), 53.

15. Haque, A.E. (2015). "Construction and Validation of a New Measure of Xenophobia". Erişim: https://audreyhaque.files.wordpress.com/2015/07/construction -and-validationof-a-new-measure-of-xenophobia.pdf, Erişim tarihi: 24.10 .2020

16. Hjerm, M. and Nagayoshi, K. (2011). "The Composition of the Minority Population As a Threat: Can Real Economic and Cultural Threats Explain Xenophobia?". International Sociology, 1-29.

17. WHO. (2016). "Migration and Health: Key Issues. Public Health Aspects of Migration in Europe." WHO Regional Office for Europe.

18. Aydoğan, S. ve Metintaș, S. (2017). "Türkiye'ye Gelen Dış Göç ve Sağlığa Etkileri.” Türk Dünyası Uygulama ve Araștırma Merkezi Halk Sağlığı Dergisi, 2 (2), 37-45.

19. Dong, Q, Day, K.D. and Collaco, C.M. (2008). "Overcoming Ethnocentrism Through Developing İnterculturel Communiction Sensitivity And Multiculturalism. Human Communication". A Publication of the Pacific and Asian Communication Association, 11 (1), 27-38.

20. Kolukırık, S. (2009). "Mülteci ve Sığınmacı Olgusunun Medyadaki Görünümü: Medya Politiği Üzerine Bir Değerlendirme". Gaziantep Üniversitesi Sosyal Bilimler Dergisi, 8 (1), 1-20. 